\title{
A low-temperature-cross-linked poly(4-vinylphenol) gate-dielectric for organic thin film transistors
}

\author{
Peter Vicca ${ }^{\mathrm{a}, *}$, Soeren Steudel ${ }^{\mathrm{a}}$, Steve Smout ${ }^{\mathrm{a}}$, Arne Raats ${ }^{\mathrm{b}}$, Jan Genoe ${ }^{\mathrm{a}}$, Paul Heremans ${ }^{\mathrm{a}, \mathrm{c}}$ \\ a Polymer E Molecular Electronics Group, IMEC, Kapeldreef 75 3001, Leuven, Belgium \\ ${ }^{\mathrm{b}}$ Katholieke Hogeschool Leuven Gezondheid E Technologie, Herestraat 49 3000, Leuven, Belgium \\ c KULeuven, Department ESAT, Kasteelpark Arenberg 10, B-3001, Leuven, Belgium
}

\section{A R T I C L E I N F O}

\section{Article history:}

Received 25 February 2010

Received in revised form 3 August 2010

Accepted 4 August 2010

Available online $\mathrm{xxxx}$

Keywords:

Microelectronics

Processing

Cross linking

Poly(4-vinylphenol)

Dielectric properties

\begin{abstract}
A B S T R A C T
We present experimental results using an alternative cross-linker for poly(4-vinylphenol) (PVP) that allows lowering of the thermal budget of the cross-linking reaction to $130{ }^{\circ} \mathrm{C}$ which compares very favorable to the $180^{\circ} \mathrm{C}$ required by the commonly used cross-linking agent poly(melamine-co-formaldehyde). Furthermore, we characterize the dielectric properties of a $200 \mathrm{~nm}$ thick layer and realize high quality organic thin film transistors using this low-temperature PVP as a gate-dielectric.
\end{abstract}

(C) 2010 Elsevier B.V. All rights reserved.

\section{Introduction}

Organic thin film transistors offer the potential of applications for electronics and active matrix back panels on foil [1,2]. The use of polymer foils limits the possible manufacturing temperature to below $130{ }^{\circ} \mathrm{C}$ for poly(ethylene terephthalate), and below $160{ }^{\circ} \mathrm{C}$ for Polyethylene naphthalate (PEN).

We prefer bottom-gate, bottom-contact transistor geometries, as with this geometry, connections between the gate metal layer and the source/drain metal layer only require via holes through the gate insulator, and furthermore the delicate organic semiconductor can be applied as last step in the transistor fabrication. In this geometry, the gate dielectric is the most challenging layer. When made of a polymer, it should be cross-linkable to withstand the impacts of solvents and bases from further process steps. The cross-linking reaction should not leave any mobile ions in the film, therefore excluding cross-linking reactions kin to the one used in photoresist. Further, the cross-linked polymer should have a very smooth surface (root mean square roughness $<1 \mathrm{~nm}$ ) [3], a high electrical field strength, preferable a high dielectric constant, high purity, and preferably be hydrophobic while still permitting sufficient adhesion to adjacent layers - precluding a teflon-like chemical structure.

There are only a handful of polymers found in literature that fulfill those requirements $[4,5]$. One of the most widely used is cross-linked

\footnotetext{
* Corresponding author.

E-mail address: Peter.Vicca@imec.be (P. Vicca).
}

PVP (Fig. 1.) which was for the first time reported by Drury [6] and later by Klauk [7]. Commonly, PVP [8] is dissolved in propylene glycol methyl ether acetate (PGMEA) and poly(melamine-co-formaldehyde) is used as a cross-linker. Subsequently the layer is spin-coated and baked on a hotplate at $180{ }^{\circ} \mathrm{C}$ or above [9].

At this process temperature even heat-stabilized PEN-foil [10] starts to shrink and causes misalignment. Furthermore, a noticeable hysteresis is present in the transistor curves, probably caused by incomplete cross-linking [11]. Recently several research groups published alternative routes how to lower the cross-linking temperature either by adding UV-light [12], incorporating silanes to the solution [13] or using a different cross-linker [14,15] or PVP derivatives [16]. We selected a series of commercially available (Sigma Aldrich) cross-linkers with secondary diamines, triazines and bis (trichlorosilanes). These have the potential to react with the alcohol group of the PVP. The cross-linkers were replacing $2 \mathrm{w} \%$ of the poly(melamine-co-formaldehyde) in a $10 \mathrm{w} \%$ PVP solution made in propylene glycol methyl ether acetate (PGMEA). The modus of preparing the experimental solutions was the same as used for the standard PVP solutions using poly(melamine-co-formaldehyde) as a cross-linker. For primary diamines, CAS 107-15-3, 462-94-2, 110-60-1 and $15520-10-2$ and secondary types of diamines, CAS 112-21-0, 63737-71-3 and 74-31-7, an instant reaction at room temperature was noticed and therefore the diamines cannot be considered as a cross-linker anymore. The bis(trichlorosilanes), CAS 13083-94-8 and 2504-64-5, were too reactive with air or were not able to withstand the solvents used in organic thin film transistor (OTFT) processing. These solvent tests were done with common processing chemicals 
<smiles>CC(C)(C)CC(C)(C)c1ccc(O)cc1</smiles>

(a)<smiles></smiles>

$\mathrm{R}=\mathrm{H}$ or $\mathrm{CH}_{3}$

Fig. 1. Chemical structure of (a) Poly(4-vinylphenol) and (b) Poly(melamine-coformaldehyde).

like acetone, isopropanol (IPA), deionized water, n-methyl-2-pyrrolidone, tetramonium hydroxide and 1-methoxy-2-propanol acetate. A selection of 1,3,5-Triazines, CAS 91-76-9, 542-02-9, 19338-12-6 and 29366-76-5, mostly failed to dissolve in PGMEA, with exception of (hydroxymethyl) benzoguanamine, HMBG (Sigma Aldrich product number 441945) shown in Fig. 2, which we choose to progress with further experiments. At first, we analyzed the film deposition by spincoating of the PVP solution with HMBG cross-linker on a glass substrate.

Spin curves were established for various cross-linker and PVP concentrations. After bake-out of the films at $180{ }^{\circ} \mathrm{C}$, the thickness of the resulting layer was measured by ellipsometry. The target thickness of $200 \mathrm{~nm}$ was reached by spin-coating a solution of a 10 w\% PVP and 2 w\% HMBG in PGMEA at $5000 \mathrm{rpm}$.

Next, the resistance of cured PVP to solvents was tested. After spincoating, the samples were cured in a vacuumoven for $3 \mathrm{~h}$ at $110^{\circ} \mathrm{C}$, $130{ }^{\circ} \mathrm{C}, 150{ }^{\circ} \mathrm{C}$ and $180^{\circ} \mathrm{C}$. Subsequently, the samples were immersed for 1 minute in acetone, isopropyl alcohol (IPA) and toluene. For curing at $130{ }^{\circ} \mathrm{C}$ or higher, the solvent had no visible impact on the film. However, when cured at $110^{\circ} \mathrm{C}$, the film was removed by rinsing in any of the tested solvents.

The chemical proof of cross-linking was established by means of Fourier transform infrared spectroscopy (FTIR, Bruker IFS $66 \mathrm{u} / \mathrm{S}$ ). Spectra were taken for non-cured and cured $\left(130{ }^{\circ} \mathrm{C}\right)$ PVP, and compared to a blank sample that acts as reference (Fig. 3 ). In these spectra, the signature of the hydroxyl group of the PVP molecule is the peak in the range of $3200-3600 \mathrm{~cm}^{-1}$. It can be observed in Fig. 3 that this peak is reduced after cross-linking PVP with HMBG at $130^{\circ} \mathrm{C}$, indicating that a certain concentration of hydroxyl groups have reacted with the cross-linker.

In a second test, we fabricated capacitor structures on glass to evaluate the leakage and breakdown of the cross-linked PVP. For this purpose, $30 \mathrm{~nm}$ Au was evaporated onto a glass substrate, defined by photolithography and wet etched with a commercial Iodine solution. Subsequently, a film of $200 \mathrm{~nm}$ cross-linked PVP was applied and baked at different temperatures. Via holes were defined in the PVP film by photolithography and dry-etched with $\mathrm{O}_{2}$-plasma. Finally, a second $30-\mathrm{nm}$ Au layer was applied by thermal evaporation, and structured by photolithography and wet etch.

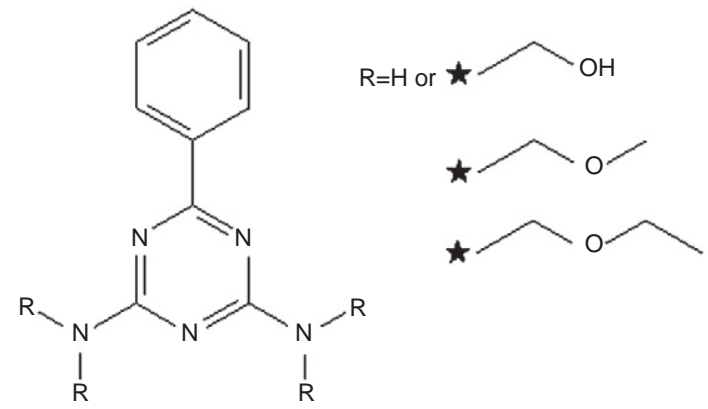

Fig. 2. Chemical structure of (Hydroxymethyl)benzoguanamine.

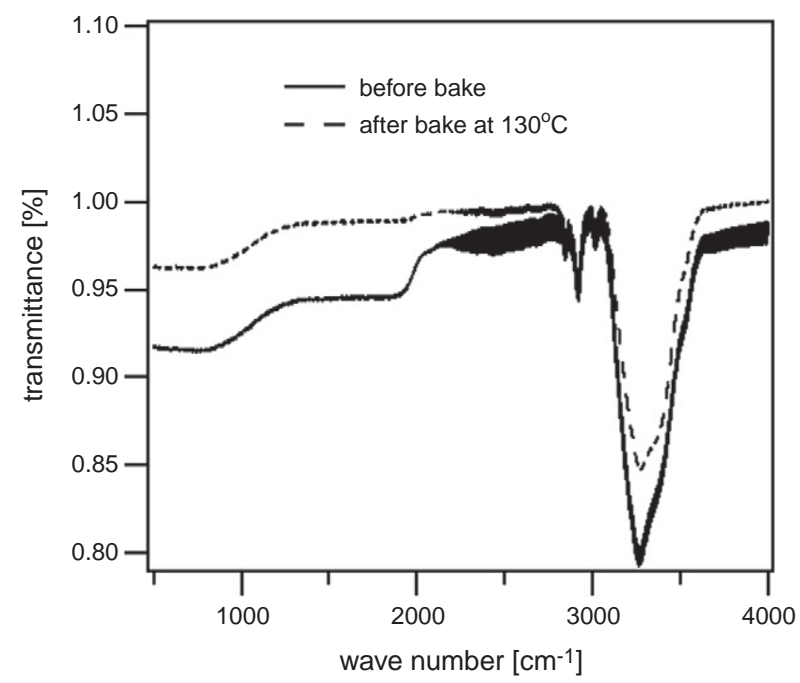

Fig. 3. FTIR spectrum of a PVP/(hydroxymethyl)benzoguamine solution before and after curing at $130^{\circ} \mathrm{C}$.

The current-voltage (IV) characteristics of the capacitors are shown in Fig. 4. The breakdown voltage and leakage of the PVP with HMBG cross-linker baked out at $130{ }^{\circ} \mathrm{C}$ are similar to those of PVP cross-linked with poly(melamine-co-formaldehyde) at $180^{\circ} \mathrm{C}$. The capacitance value measured with quasi-static CV measurements corresponds to a dielectric constant of 4.5 .

In a subsequent step, we made top-contact OTFTs using evaporated pentacene as a semiconductor to evaluate the compatibility of the lowtemperature cross-linked PVP in a transistor process. We used a highly doped $\mathrm{Si}$-wafer covered with $140 \mathrm{~nm}$ thermal grown $\mathrm{SiO}_{2}$ as substrate. The PVP solution with HMBG cross-linker was spin-coated and baked at different temperatures. Afterwards, $30 \mathrm{~nm}$ of pentacene was deposited by organic molecular beam deposition on the samples as the organic semiconductor. Source-Drain contacts were realized by depositing $100 \mathrm{~nm}$ Au through a shadowmask. Electrical measurements were performed with a Keithley 4200 probe station in a nitrogen glovebox.

Fig. 5 shows that the transistor characteristics are similar at every temperature in excess of $130^{\circ} \mathrm{C}$ and the mobility reaches $10^{-1} \mathrm{~cm}^{2} / \mathrm{Vs}$ comparable to what has been shown before with the standard PVP cross-linker. The threshold voltage however is below $-6 \mathrm{~V}$, whereas for circuit applications a threshold voltage closer to $0 \mathrm{~V}$ would be preferred [17]. In an independent experiment, we varied the concentration of poly

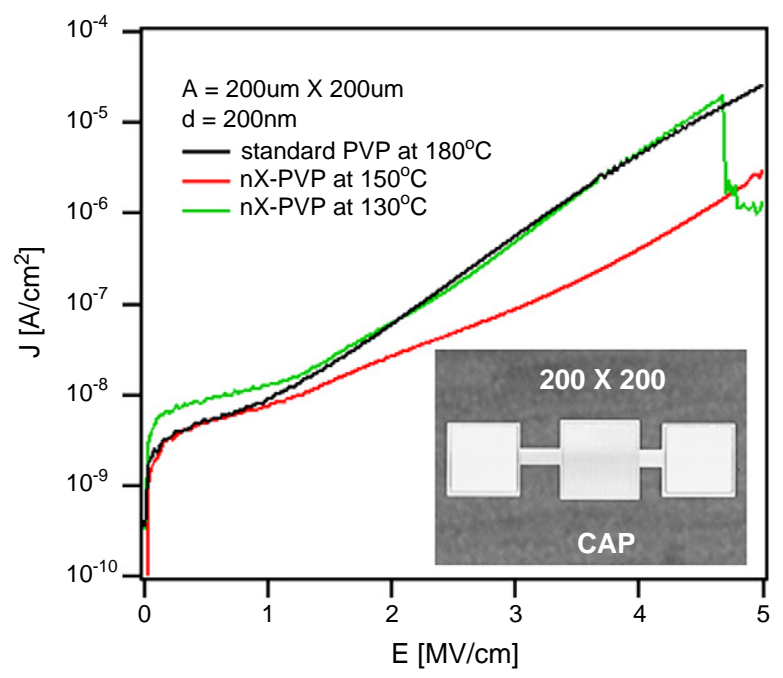

Fig. 4. Leakage and breakdown test for $200 \mathrm{~nm}$ cross-linked PVP (standard=poly (melamine-co-formaldehyde); $\mathrm{nX}=\mathrm{HMBG}$ ); (inset) microscopic image. 


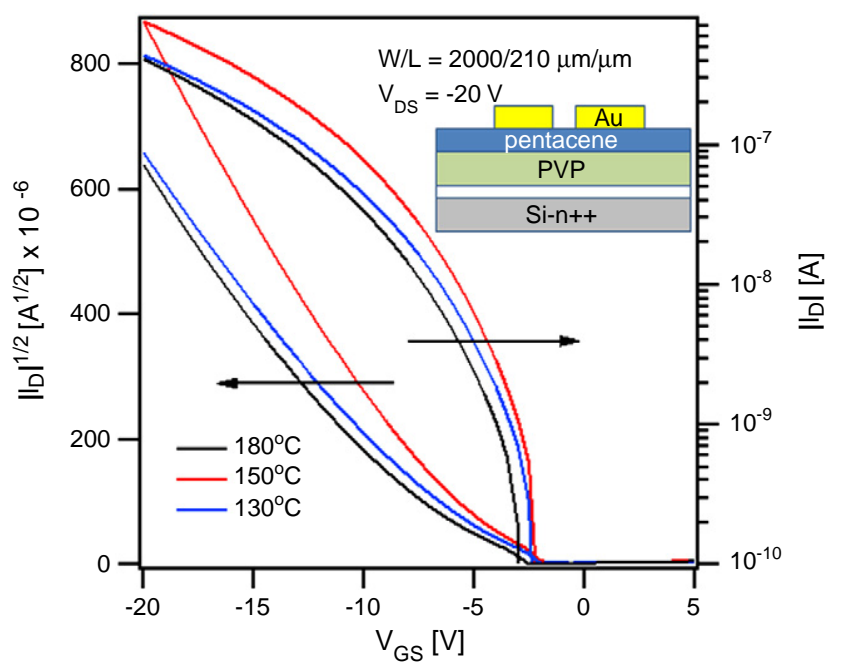

Fig. 5. Electrical characteristics ( $I_{D S}$ vs. $V_{G S}$ ) of top-contact OTFTs for different PVP cross-linking temperatures $\left(\mu \sim 10^{-1} \mathrm{~cm}^{2} / \mathrm{Vs}, \mathrm{V}_{\mathrm{T}} \sim-6 \mathrm{~V}\right)$; (inset) schematic cross-section of device structure.

(melamine-co-formaldehyde) in PVP and observed that the threshold voltage is correlated with the amount of cross-linker, while the mobility is not much affected (Fig. 6). This result will be used as a starting point for optimizing the HMBG concentration in the PVP mixture.

Next, we investigated cross-linked PVP for transistor geometries where the source and drain contacts are defined by photolithography directly on top of the cross-linked gate insulator (so-called "bottomcontact" transistors). The bottom contact transistor structure is closer to the processflow of an integrated circuit [2] as compared to top contact test structures, because photolithography allows to define transistor channels down to $5 \mu \mathrm{m}$ (see the inset of Fig. 7). The PVP was cross-linked with different amounts $(0.5 ; 1 ; 1.5$ and 2 w\%) of (hydroxymethyl)benzoguamine and all were cured at a temperature of $130{ }^{\circ} \mathrm{C}$. Before the pentacene deposition a surface treatment [18] was performed. The electrical measurements of these OTFT are shown in Fig. 7. These transistors are well behaved with a mobility of around $0.55 \mathrm{~cm}^{2} /$ Vs. Using a cross-linker concentration of $1.25 \mathrm{w} \%$, a $\mathrm{V}_{\mathrm{T}}$ of $1.6 \mathrm{~V}$ was achieved.

In summary, we described the use of an alternative cross-linker for PVP that allows to decrease the cross-linking temperature to $130^{\circ} \mathrm{C}$, while maintaining good electrical characteristics of the transistors. We demonstrated fully photolithographically patterned bottom-gate

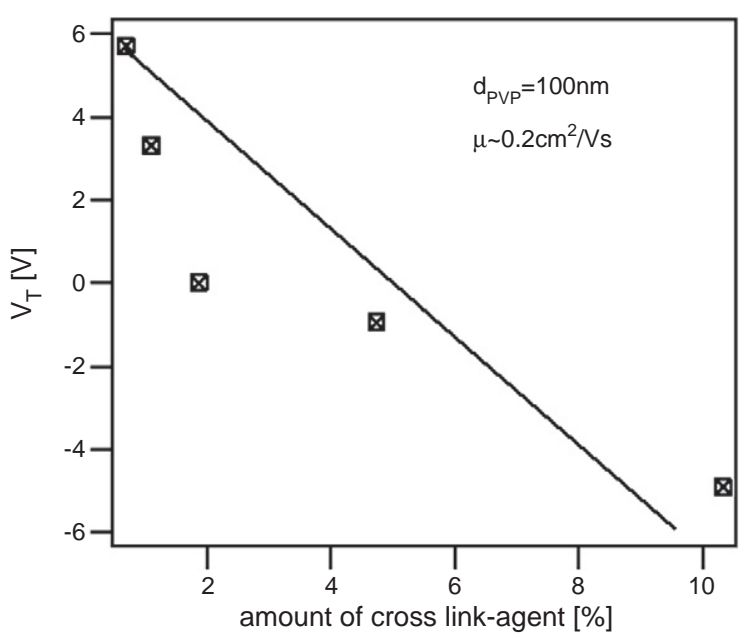

Fig. 6. Effect of concentration of cross-linker in PVP on the threshold voltage in a pentacene top-contact OTFT.

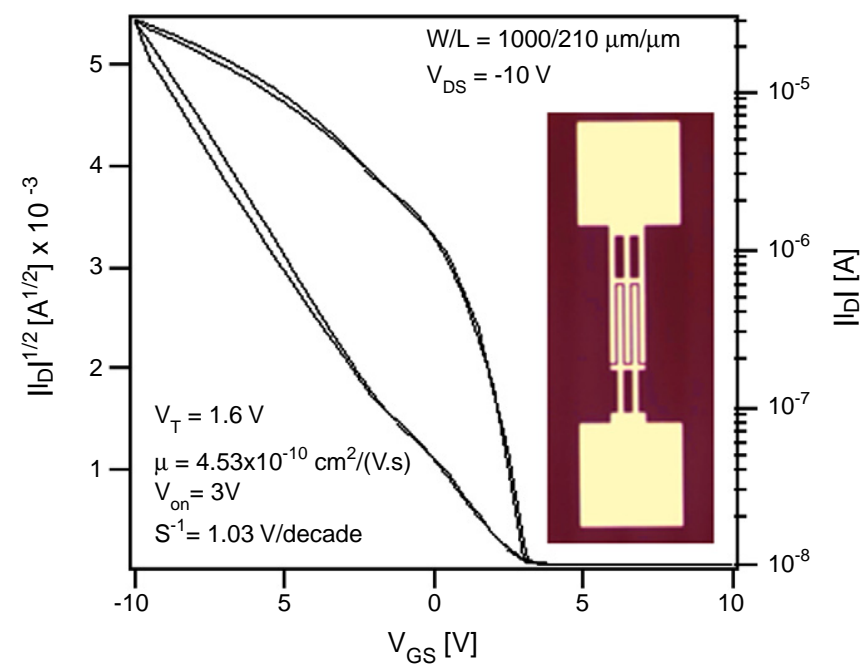

Fig. 7. Electrical characteristics ( $\mathrm{V}_{\mathrm{GS}}$ vs. $\mathrm{I}_{\mathrm{DS}}$ ) of a bottom contact OTFT with PVP cross-linked at $130{ }^{\circ} \mathrm{C}$; (inset) microscopic image.

bottom-contact transistors with this cross-linked PVP as gate dielectric, with charge carrier mobility of over $0.5 \mathrm{~cm}^{2} / \mathrm{Vs}$.

The authors would like to acknowledge the financial support of the European project Flame (ICT-216546).

\section{References}

[1] I. Yagi, N. Hirai, M. Noda, A. Imaoka, Y. Miyamoto, N. Yoneya, K. Nomoto, J. Kasahara, A. Yumoto, T. Urabe, Proc. SID Conf. (2007) 1753.

[2] G.H. Gelinck, H. Huitema, A. Edzer, E. van Veenendaal, E. Cantatore, L. Schrijnemakers, J.B.P.H. van der Putten, T.C.T. Geuns, M. Beenhakkers, J.B. Giesbers, B.H. Huisman, E.J. Meijer, B.E. Mena, F.J. Touwslager, A.W. Marsman, B.J.E. van Rens, D. M. de Leeuw, Nat. Mater. 3 (2004) 106.

[3] S. Steudel, S.D. Vusser, S. De Jonge, D. Janssen, S. Verlaak, J. Genoe, P. Heremans, Appl. Phys. Lett. 85 (2004) 4400.

[4] T. Yasuda, K. Fujita, H. Nakashima, T. Tsutsui, Jpn. J. Appl. Phys. vol. 42 (2003) 6614.

[5] Y. Yun, C. Pearson, M.C. Petty, J. Appl. Phys. 105 (2009) 034508.

[6] C.J. Drury, C.M.J. Mutsaers, C.M. Hart, M. Matters, D.M. de Leeuw, Appl. Phys. Lett. 73 (1998) 108.

[7] H. Klauk, M. Halik, U. Zschieschang, G. Schmid, W. Radlik, Proc. IEDM Conf. (2002) 557.

[8] Sigma Aldrich, Poly(4-vinyl phenol), CAS 24979-70-2, average Mw 25, 000.

[9] M. Hwang, H.S. Lee, Y. Jang, J.H. Cho, S. Lee, D.H. Kim, K. Cho, Macromol. Res. vol. 17 (No. 6) (2009) 436.

[10] Heat stabilized PEN foil Teonex® by DuPont Teijin Films.

[11] S.C. Lim, S.H. Kim, J.B. Koo, J.H. Lee, C.H. Ku, Y.S. Yang, T. Zyung, Appl. Phys. Lett. 90 (2007) 173512-1.

[12] P. Liu, Y. Wu, Y. Li, B.S. Ong, S. Zhu, J. Am. Chem. Soc. 128 (14) (2006) 4554.

[13] S. Mototani, S. Ochiai, X. Wang, K. Kojima, A. Ohashi, T. Mizutani, Jpn. J. Appl. Phys. vol. 47 (No. 1) (2008) 496.

[14] M.E. Roberts, N. Queralto, S.C.B. Mannsfeld, B.N. Reinecke, W. Knoll, Z. Bao, Chem. Mater. 21 (2009) 2292.

[15] Z. Bao, Mater. Matter vol. 2 (No. 3) (2007) 4

[16] J. Jang, S.H. Kim, S. Nam, D.S. Chung, C. Yang, W.M. Yun, C.E. Park and J.B. Koo, Hysteresis-free organic field-effect transistors and inverters using photocrosslinkable poly(vinyl cinnamate) as a gate dielectric, Appl. Phys. Lett., Vol. 92, 143306-1 - 143306-3.

[17] S. De Vusser, J. Genoe, P. Heremans, Proc. IEEE Conf. ED 53 (4) (2006 April) 601.

[18] S. Steudel, S. De Vusser, K. Myny, M. Lenes, J. Genoe, P. Heremans, J. Appl. Phys. 99 (2006) 114599. 